\title{
Conclusion: The Future of Anti-Rape Activism
}

\section{Introduction}

In the time since this project was completed, rape and sexual violence has occupied a significant position on the public agenda, with digital media playing a vital role in not only bringing the issue into the public sphere but also sustaining the conversation. The \#MeToo movement, which emerged in October 2017, was quickly followed by the \#TimesUp movement seeking to address the prevalence of sexual assault and harassment in Hollywood. One year after \#MeToo began trending on Facebook and Twitter, the hashtag \#WeBelieveHer became popular following the appalling treatment of Dr Christine Blasey Ford, who accused then-US Supreme Court nominee Brett Kavanaugh of sexually assaulting her when she was 15 years old. Beyond the confines of North America, a plethora of other popular digital campaigns - some inspired by \#MeToo, others more reflective of their local contexts - have emerged and garnered significant support around the world.

Shortly before I submitted this manuscript for publication, the Weinstein Trial began. Images circulated around the world of a 'broken man' using a walking frame to shuffle in and out of court. Multiple survivors took the stand in court to testify to the abuse and violence they experienced from him, and he was eventually convicted of rape in the third degree and a criminal sex act in the first degree (Pierson, 2020). Despite the multitude of survivors who spoke out at the time the \#MeToo hashtag was trending and impact this had on compelling submerged online networks into action, it is the outcome of his trial that the 'success' of the \#MeToo movement has been publicly judged (Pierson, 2020). Subsequently, the broader agenda and effects of the \#MeToo movement - however loosely defined or impactful they have been - have been considered 'complete' or at least positioned as partially victorious (Pierson, 2020). However, for most survivors and activists, the fight is far from over. This is why it is so important to continue to explore the sites of resistance that exist outside of moments of mass protest or response and to critically examine the ways in which these digital spaces are engaged in making the personal political, as I have done in this book.

\footnotetext{
Online Anti-Rape Activism: Exploring the Politics of the Personal in the Age of Digital Media, 143-153

Copyright $(\mathcal{2 0 2 0}$ by Rachel Loney-Howes. Published by Emerald Publishing Limited.

This work is published under the Creative Commons Attribution (CC BY 4.0) licence. Anyone may reproduce, distribute, translate and create derivative works of this work (for both commercial and non-commercial purposes), subject to full attribution to the original publication and authors. The full terms of this licence may be seen at http://creative commons.org/licences/by/4.0/legalcode
} doi:10.1108/978-1-83867-439-720201009 
I have argued that online spaces are useful tools for furthering anti-rape politics, highlighting a spectrum of digital media campaigns engaged in anti-rape activism to unpack and explore the nuances and complexities associated with engaging and sustaining these projects beyond moments of mass mobilisation and high-profile cases. Drawing on the rich and complex history of anti-rape activism dating back to the 1970s, this book has illustrated the ways in which these digital projects engage with the politics of the personal in the face of critiques pertaining to carceral feminism and neoliberalism. I have demonstrated the various ways those involved in these online anti-rape campaigns attempt to be heard, seen and believed from forming anti-rape networks through consciousness-raising, fostering peer-to-peer witnessing, to broadening the modes of representation and offering alternative pathways for practising justice. In doing so, I have highlighted the ways these online anti-rape spaces are continuously oscillating between - and attempting to reconcile - the personal and the political in the age of digital media. What has emerged from this project is a complex reading of the nature, use and scope of online spaces for anti-rape activism. While small in scale, this book points to both the potentials and limitations of these online anti-rape activist spaces and depicts a nuanced reading of anti-rape activism that is not inherently a reflection of a carceral or neoliberal feminist agenda. Rather, it is broad and multifaceted, with activists engaging with and navigating these challenges in complex and creative ways that also reveal the precarity and porous nature of digital feminism.

While \#MeToo has changed the landscape of digital feminist activism, it could not have done so without activists like the case studies involved in this book, paving the way for it to emerge. In other words, the case studies presented in this book highlight the significant contribution digital submerged networks play in facilitating moments of mass mobilisation, sustaining consciousness-raising and supporting victim-survivors long after rape and sexual violence are off the public agenda. Therefore, in concluding this book, I wish to reflect on some of the overarching dynamics that have been salient across the chapters before turning to the impact of the \#MeToo movement and the future of anti-rape activism. I first draw attention to the notion of 'authenticity' in these online anti-rape campaigns through their attempts to articulate and broaden what rape looks like and who can assume the identity of a 'real' rape victim, followed by a discussion about the ways these spaces seek to curate particular anti-rape messages. Second, I reflect on the persistent onus on women to take responsibility for being raped, highlighting the pervasive undertones of the 'personal responsibility' discourse associated with neoliberalism, as well as the enduring challenges faced by activists and crisis services to move beyond rape as 'women's problem.' Finally, in concluding this book, I reflect on the future of anti-rape activism in a post-\#MeToo world. Drawing on the analysis conducted throughout this book, I consider on the challenges, complexities and opportunities for anti-rape activism and the enduring role of digital media in navigating the personal and the political.

\section{Curating Authenticity in Online Anti-Rape Activism}

In many ways, the case studies in this book have been heavily concerned with the notion of 'authenticity.' One of the key challenges for feminist activists creating content in digital environments is the balancing act required in developing 
a particular individualised brand and advancing a collective political agenda (Banet-Weiser, 2018; Pruchniewska, 2018) - and the key element for a successful 'brand' (or curating a particular message, as I discuss below) is authenticity. This particular form of authenticity is heavily associated with neoliberalism; however, one of the compelling elements of the way 'authenticity' was utilised in the case studies involved in this project was not so much about selling a particular brand of activism or feminism, but rather about challenging culturally approved assumptions about 'authentic' activism, rape, victim-survivors, and justice seeking.

In the first instance, participants in this study sought to assert that their approach to claims making were 'authentic', 'real' or 'genuine.' I discussed in Chapter 3 the ways online activism has been criticised for fostering a culture of slacktivism in which participants have little understanding of the complexity of social problems, or offer superficial means of contributing to the movement, and as such is considered by some scholars to not be 'real' activism. Yet, Angela was insistent that the Pixel Project was a 'real' or authentic form of activism and not slacktivism; 'liking' or 'sharing' on social media sites is a way of determining how popular your message is and functions as a gateway to getting individuals more involved in the cause (see also Mendes, Ringrose, et al., 2019, who support this position). Conversely, Katie felt that her blog, These Are Not My Secrets, was not 'activist enough' and did not want to elevate herself to the 'status' of being an online activist. Here, Katie is pointing to an assumption that there is an authentic subjectivity of an 'online activist' and a 'real' or correct way to connect the personal to the political.

A further way in which the notion of authenticity arose was in Chapter 4, where I demonstrated how most victim-survivors' experiences fall outside hegemonic expectations about 'authentic' rape, and the significant role digital space plays in helping to rewrite the rape script in ways that are more authentic or true to victim-survivors' experiences. While activists, such as Maya, feared their contestations of the hegemonic scripts might not gain recognition, they also felt compelled to remain authentic to their experiences, to be as truthful as possible and not to gloss over the 'difficult bits.' Hypatia, in particular, had gone to great lengths to articulate why her experience of rape is still 'real' even if it does not look like conventional assumptions about rape and rape-trauma.

In developing this point around shifting the rape script and challenging notions of authenticity in relation to 'real' rape', Chapter 5 demonstrated the ways these online spaces resist or challenge the notion of the 'good victim', who is held up as the 'authentic' victim in neoliberal victim discourse. In particular, I discussed how these online spaces resist representing victim-survivors in ways that focus on their inherent victimisation because, as Angela argued, it is 'disrespectful to survivors', opting instead to use language and imagery that signifies their strength, empowerment and resilience. Other spaces, like the Rape Crisis Scotland campaigns, sought to subvert the logics of the good victim by challenging the victim-blaming discourses that position women as 'asking to be raped.' However, in their attempts to subvert or recast the depiction of a 'good' victim, some of these online spaces reinforce an assumption that 'real' victim-survivors of rape are typically heterosexual, white women. These exclusionary practices did not occur across the board, however: Project Unbreakable, for example, was a notable 
standout when it came to representing a diverse range of victim-survivors of sexual violence. Nonetheless, the failure to accommodate LGBTQ victim-survivors perpetuates not only assumptions about 'real' rape but also 'real' women.

Lastly, authenticity also emerged in relation to the question of 'justice.' In Chapter 6, I explored how these online anti-rape spaces challenge the criminal justice system as the site of 'real' justice. Specifically, I discussed how these online campaigns help to broaden the scope of justice beyond the criminal justice system, as well as operate as sites of critique of the power that the criminal justice system possesses to impart recognition. The question of authenticity also emerged with respect to using (or not using) one's real name online. The provision of anonymity was perceived as one of the most important features of the online space for these anti-rape activists because it provided them with protection so that they could speak their 'truths' and enunciate a challenge to the real causes of rape without people finding out their real identities. While anonymity might protect activists from harassment or negative reactions offline, safety online remained a concern for some participants because of the ease of accessibility of many of these activist spaces. In this sense, the operation of authenticity in these anti-rape activist spaces seems to be about fostering honesty, intimacy, support and privacy in order to advance a collective agenda.

The aforementioned approaches to authenticity were part of these digital campaigns' attempt to curate a particular anti-rape message. However, this curation was not necessarily about developing a particular 'brand', although some sought to sell a particular type of feminism. Rather, curating these digital spaces was about creating safe spaces for victim-survivors or for ensuring that discussions did not get out of control. I highlighted in Chapter 4, for instance, that in addition to peer-to-peer witnessing, in which victim-survivors witness the coming out and claiming of experience of other victim-survivors, negative witnessing also occurs in these online spaces. While some of this negative witnessing, as Hypatia outlined, was not inherently bad because it did offer an opportunity to help educate people misguided about rape due to the influence of rape culture, trolling nonetheless remained a problem for these online anti-rape campaigns. Subsequently, a significant amount of labour is involved in maintaining a certain standard of acceptable discussion in these online spaces to keep out the trolls and rape apologists. The upshot of the constant surveillance carried out by the moderators of these online anti-rape campaigns means that a highly curated message is presented to the public, reinforced through the modes of representation.

There also existed a perception by some of the managers of the case studies involved in this project that many online feminist projects using a 'fighting' response to rape and rape culture cripple their activism. For example, in Chapter 5, I highlighted how Alana and Angela wanted to take a more 'rational' rather than a 'fighting' or 'militarist' approach to their activism in order to present a more unified front, as well as to distance themselves from what were perceived as historically radical feminist approaches to anti-rape activism. Angela specifically was concerned that a 'fighting' response results too often in 'bloodshed' with feminists subsequently accused of being 'feminazis' and 'men not listening' to the claims being made, stymying any potential for change. Moreover, both 
Katie and Angela noted that there was a significant amount of 'in-fighting' between feminists online, which means, according to Angela, that some moderate feminists feel they cannot voice their opinion for fear they will be attacked by other more 'radical' feminists. This point ties in with what I suggested above about authenticity. For instance, Katie expressed that in arguing with each other about whose experience or subjectivity is more 'authentic' (for instance, a trans-woman's experience of rape is considered less 'authentic' than a cisgender woman's), feminists fail 'to focus on the things that affect all of us' such as patriarchy, for example. As a result, fighting with other activists as well as presenting a 'fighting' response was perceived to hinder significantly antirape activism's capacity to bridge the divide between the personal and the political. Thus, there is a balancing act playing out in these online spaces between freedom and control, which seems to echo the contradictions inherent in the desire to both present discourses of rape in an authentic or real way and resist the idea that there is such a thing.

\section{Rape as 'Women's' Responsibility}

While rape has been substantively on the public agenda for nearly four decades, the problems that emerged in response to second-wave anti-rape activism continue to undermine activist efforts. To varying degrees, activist efforts to provide greater support for victim-survivors, as well as reform the criminal justice system, have been responded to in Western democracies. However, access to funding remains tenuous, and law reform projects are criticised or have been appropriated by a carceral neoliberal agenda. Moreover, efforts to engage in a productive dialogue about the sociocultural causes of rape, such as the objectification of women's bodies - regardless of sexuality - and the disregard for their autonomy, remain contentious, with the focus barely shifting from rape as something random and perpetrated by a stranger. Where perpetrators are known to the victim, they are presented as monstrous, pathological, sick or deviant subjects who took advantage of vulnerable women - the imagery and journalist reporting on Harvey Weinstein in the wake of the \#MeToo movement made particularly good use of these tropes (Royal, 2019). Rape is thus positioned in individualistic, a-political terms - as a 'woman's problem' to solve. The material presented in this book very much highlights this tension, indicating that while certain elements of anti-rape activism have changed, the influence of neoliberal discourses, such as risk management and personal responsibility, continues to hold sway over public perceptions of rape. Although this speaks to what Rose Corrigan (2013) argues, that the anti-rape movement has been a successful failure - and indeed what Hypatia outlined at the beginning of this book that little has changed for women - activists clearly continue to fight tirelessly to resist and challenge these discourses. In this sense, I would argue that rather than having ceded ground to neoliberalism, activists with in the anti-rape movement are, to varying degrees, conscious of these challenges relating to the ways in which survivors continue to remain responsible for preventing rape in particular - as well as speaking out about rape - and sought to address these in creative ways. 
Nonetheless, most of the online anti-rape campaigns examined in this book carried out their projects in the absence of men. While these spaces did not outright exclude men, the overwhelming majority of people who participated in them identified as 'women.' In some ways, this inadvertently re-responsibilises women, and the onus thus remains on primarily women and other survivors to speak out about and prevent rape, despite evidence that many of the causes of rape lie at the heart of structural masculinity (Bedera \& Nordmeyer, 2020; Brownmiller, 1975; Campbell \& Wasco, 2005; Mardorossian, 2014). It was clear on the discussion broads associated with the Rape Crisis Scotland campaigns that attempts by activists to shift this responsibility were heavily resisted, yet at the same time, there was also opposition to the idea of (heterosexual) women as sole victim-survivors. For example, many of the comments in the forums queried the lack of representation of men as victim-survivors in their campaigning, as well as reinforcing women's personal responsibility for managing their own risk in order to prevent rape. Bloggers in this project also resisted the responsibility rhetoric by engaging in a discussion about the broader sociocultural causes of rape. Hypatia, for example, was outspoken on her blog about the role of masculine sexual entitlement as the cause of most rapes - including her own, not her mode of dress, alcohol consumption or relationship to the perpetrator. In addition, Hypatia also noted how women are conditioned not to call their experiences rape. However, rather than showing a willingness to engage in a discussion about rape myths and rape culture, these issues were regularly dismissed by some commenters as not 'real' problems, and rape would be prevented if women simply took greater responsibility for their own personal safety. Again, this question of authenticity emerges, with rape culture not being perceived as the 'true' cause of sexual violence. Given the persistent resistance to recognising the role structural and cultural tropes of masculine dominance continue to play as factors underlying the causes of sexual violence, it is admirable that the activists continue to push back against the failure of many to ethically listen, witness and respond to activists' claims.

This failure to witness activists and victim-survivors extends to the realm of the political, not just everyday people interacting online. Under neoliberalism, the feminist movement has been recast by the state as a 'special interest group', and subsequently, sexual violence has largely disappeared from public policy (Gotell, 2007). While rape crisis centres have relied on volunteers throughout their histories, the increasing withdrawal of financial and political support from the state under neoliberalism has meant that centres have had to channel the minimal amount of funding they do have into providing support services for victim-survivors rather than construct public campaigns aimed at challenging sociocultural attitudes. Rape crisis services in England and Wales continue to have their funding slashed, and in Australia crisis services, such as 1800 Respect, regularly request donations in order to continue to provide support and advice to victim-survivors. In addition, funding in many Western contexts is often contractual and requires evidence-based evaluations to support funding renewals - it is far easier to present how many victim-survivors a service has supported rather than how many sexual assaults have been prevented or attitudes changed. As a 
result, much of the anti-rape activism happening in these online spaces is grassroots and volunteer-led. Thus, anti-rape activism in the online context is heavily dependent on volunteers. There were the exceptions of the Rape Crisis Scotland and Stop Rape in Conflict campaigns, which receive state and international financial support to develop their projects. In this sense, anti-rape activism is rendered a 'special interest group' rather than a sole object of policy and reform, and campaigns have to compete with other 'special interest groups' when applying for funding to create and sustain their activism. It is therefore remarkable how resilient sexual assault and rape crisis support services have been in the face of precarious futures and is a reflection of their political commitments to assisting victim-survivors (see also Vera-Gray, 2019), but nonetheless maintains the position that it is women's - and survivors' - responsibility to address the harms of rape in particular.

In order to address the ways in which rape continues to be positioned as a 'women's problem' to solve, what is needed is a greater focus on fostering ethical listening and witnessing to ideas and the experiences of others that might present themselves as 'strange and unfamiliar rather than always and already known and knowable' (Serisier, 2018, p. 193). In particular, the power of witnessing that results from the response-ability nature of digital platforms is something this book has attempted to highlight, with Chapter 4 demonstrating the capacity of online spaces to help shift ideas about the hegemonic rape script through speaking out in different ways. Chapter 5 also sought to illustrate the ways digital spaces challenge assumptions about victimisation and survivorship - albeit in ways that are not unproblematic. As such, in order for online anti-rape activism to generate transformative approaches that shift rape away from being a 'women's problem', acts of listening and witnessing need to be intersectional in its approach. This means accounting for the hidden activists and victim-survivors of rape whose experiences and claims making are routinely dismissed or overlooked, including experiences of LGBTQ survivors, women of colour, older women, women from marginal and lower socio-economic backgrounds, women with disabilities and women located in isolated geographic locations. It is through witnessing these voices and experiences that the structural conditions and causes of sexual violence, such as patriarchy, masculinity, capitalism, racism and colonisation, will be exposed.

\section{Online Anti-Rape Activism in a Post-\#MeToo World}

This book has illustrated that despite claims that anti-rape activists are too invested in a carceral feminist agenda or has ceded ground to other elements of neoliberalism, the anti-rape movement in the online context is engaged in a broad spectrum of practices that seek to challenge the hegemonic discourses that govern the ways in which rape can be spoken about in the public sphere. In particular, this book has captured how these online spaces highlight the power of hegemonic discourses to regulate how rape and rape culture is conceptually and popularly understood. I suggested that these online spaces both subvert and reproduce these discourses, and I have argued that this simultaneous subversion and reification speaks to the tension between the personal and the political - the individual 
and the collective - in seeking recognition of rape on an interpersonal level and a sociocultural one. This tension between the personal and the political is what makes the anti-rape movement compelling and complex, and in concluding this book, I want to turn to consider the future of online anti-rape activism in a post\#MeToo world. In particular, I want to reflect on what digital spaces, like the ones discussed in this book, can offer activists in the wake of \#MeToo, to provide some 'materials through which future movements and activist practices can be imagined' (Rentschler \& Thrift, 2015, p. 242).

Although I do not wish to claim that the discussion and findings presented in this book are a reflection of online anti-rape sites in general, they still nonetheless speak to some of the broader, ongoing issues associated with anti-rape activism, specifically in relation to whose voices and experiences are captures in digital spaces. The majority of case studies involved in this project were predominantly (although not exclusively) white, middle-class women of North American and Anglo-European origin. The same critiques were levelled at the \#MeToo movement in response to the revelation that 'me too' was something initially orchestrated by Tarana Burke in 2006 as part of her work with young African-American women and girls experiencing sexual violence. The co-option of Burke's tagline, despite being problematic in itself, was less significant than the fact that it revealed the continued failure to witness women of colour's experiences of sexual violence and the tireless efforts of activists working in these communities (Fileborn $\&$ Loney-Howes, 2019). Many of these victim-survivors' experiences are underscored by continued histories of racism, colonisation, poverty and other intersecting forms of marginalisation that 'fit' even less within culturally approved or 'social filters' (Serisier, 2018, p. 192) described in Chapter 4. In order to advance a truly transformative politics of recognition, experiences and positions of intersectionality need to be at the forefront of anti-rape activism - online and offline moving forward.

The issues arising from the whiteness of anti-rape activism are further compounded by the cis-gendered and heterosexual nature of representation within these digital spaces. The lack of LGBTQ inclusion in the \#MeToo movement and the online anti-rape spaces involved in this project is concerning. Not only does it reinforce heterosexuality as the normative context in which rape occurs, but it also suggests the only 'real' cis-gendered women can experience rape. Although one of the case studies, Rape Crisis Scotland, expressed a desire to include LGBTQ experiences in future campaigning, they have not done much targeted campaigning around this issue. The assumption expressed by Angela that lesbian and transgender women have special needs when it comes to supporting them through their experiences of rape is surely incentive enough to find volunteers with those skills or at least acknowledge in activism the levels of sexual violence experienced by the LGBTQ community. Moving forward, anti-rape activists should continue to broaden the modes of representation and inclusion not just at the level of what counts as 'rape' but also whose subjectivity counts as a legitimate rape victim-survivor.

As I indicated in the introduction of this book, the data from the case studies were collected between two periods of mass mobilisation in relation to sexual 
violence: SlutWalk and the \#MeToo movement. These case studies therefore illustrate the potential of digital media to help sustain submerged anti-rape networks and consciousness-raising when the spotlight is no longer on sexual violence. While moments like \#MeToo can inspire crowds and generate significant public discussion (Papacharissi, 2015), they are merely ruptures or moments that create the possibility for intervention and response (Fileborn \& Loney-Howes, 2019). Most online anti-rape activism will never reach the kind of profile achieved by the \#MeToo movement; however, the 'connecting, dialoguing, and finding solidarity with others' (Mendes, Ringrose, et al., 2019) illustrates these digital networks' capacity to engender social change - even if only on a small scale. It is the submerged digital networks, like the case studies explored in this book, that carry out the tireless, grinding work of sustaining consciousness-raising, maintaining spaces for victim-survivors to speak out about their experiences, engage in more ethical modes of representation and foster alternative avenues for seeking justice.

The challenges for sustaining momentum and interest in social justice issues in the digital sphere are not dissimilar to traditional 'offline' social movements, yet as also I noted in the introduction of this book, online activism continues to face criticism for being too ad hoc and ephemeral. It is significant to note that half of the case studies included in this study remain active online or their projects have evolved. Some are no longer active - or have at least gone into abeyance, despite the popularity of the \#MeToo movement, such as the blog These Are Not My Secrets. Project Unbreakable too no longer receives submissions, although following the election of Donald Trump in November 2016, they briefly reopened the Tumblr blog for new submissions, and all the previous submissions are still publicly accessible. The blog YesWeSpeak was also deactivated in 2016, although the author continues to remain active on Twitter. The Pixel Project maintains a strong presence on social media, and Hypatia, author of the blog Herbs and Hags, periodically writes new posts about rape culture. Others have evolved their projects. Rape Crisis Scotland continues to develop new campaigns in addition to This Is Not an Invitation to Rape Me and Not Ever, including one called 'I just froze', and the International Campaign to Stop Rape and Gender Violence in Conflict has morphed into a new campaign called Beauty in the Middle. Healing Courage, who started out as a micro-blogger on Twitter, has now founded her own non-profit in San Francisco supporting survivors and continues to develop her online presence. In this sense, it is clear that online spaces engaged in anti-rape activism are vital networks for generating and sustaining activism and have the capacity to do so for extended periods. The evolution of Healing Courage also reflects the significance of digital spaces in helping survivors to construct their activist identities (Baker \& Bevacqua, 2018; Mendes, Ringrose, et al., 2019).

One of the key issues raised in this book, along with the \#MeToo movement, is the persistent challenges experienced by victim-survivors when reporting sexual assault either formally or informally. In Chapter 6, I showed a small number of examples of the barriers faced by victim-survivors when disclosing their experiences to the police or even friends and family members. As such, many of these online spaces, and mass movements like \#MeToo, function in ways akin to informal reporting, and disclosure in online spaces may provide victim-survivors with 
a sense of justice (see Fileborn, 2016). However, participants in this project also noted that using online spaces were not necessarily safe pathways for achieving justice, despite Chapter 4 illustrating just how politically subversive and personally transformative having a space in which to 'come out' and disclose one's experience can be. In addition, peer-to-peer witnessing - and specifically victimsurvivor-to-victim-survivor recognition - provides victim-survivors the opportunity to label their experience 'rape' when it does not 'fit' within the parameters of normative socio-legal discourses (see also O'Neill, 2018). Research suggests that victim-survivors often take years, if not decades, to disclose their experiences of sexual assault for a variety of different reasons - some of these include the fear they will not be believed, shame and humiliation and fear of retaliation from the perpetrator (Ceelen et al., 2019; Gebicki et al., 2017; Jordan, 2008). The popularity of online spaces for disclosing and informally reporting sexual assault demonstrates their capacity to sidestep some of the challenges that emerge when formally reporting sexual assault. Although the use of digital platforms for informally reporting are not without their problems, and may potentially cause further legal issues for victim-survivors if they were to out perpetrators online, the opportunity to be heard through the telling of one's story in a way that is meaningful and validates experiences is one of the most powerful justice needs of survivors of sexual violence (Clark, 2010; Fileborn, 2014, 2016; O’Neill, 2018; Wånggren, 2016). For many, receiving this kind of support and validation may be more powerful than the recognition that may come from a positive criminal justice response, and moving forward digital spaces will remain significant sites of informal justice victim-survivors.

In rounding off these reflections moving forward for online anti-rape activism, a question mark remains over the involvement of men as a means of challenging assumptions that rape is a 'women's problem' to solve as mentioned above. As I discussed in Chapter 5, rape is not a 'men's' or 'women's' issue to address; rather, it is a broader structural problem with respect to hegemonic masculinity that positions women as passive sexual objects and men as agents and sexually aggressive subjects. Greater attempts to involve men and women in dialogue with each other in responding to rape culture are needed in order to address the prevention of sexual violence (Flood, 2003; Moynihan et al., 2015). Michael Flood suggests that \#MeToo movement asks three things of men: First, to listen to women and recognise that men's violence against women is common, serious and wrong; second, \#MeToo asks that men reflect on and change their behaviour as well as their interactions with women; and third, \#MeToo asks men to contribute to social change by calling out the behaviour of other men and challenging the structural inequalities that 'form the foundation of sexual harassment and abuse' (Flood, 2019, pp. 285-286). However, despite the popularity of the \#MeToo movement, there remains significant resistance from men to acknowledging the pervasiveness of sexual violence and the existence of rape culture. For example, the hashtag \#HowIWillChange, which emerged in response to \#MeToo as a way of attempting to engage boys and men in the prevention of violence and their role in sustaining rape culture, was met with trepidation and outright backlash (PettyJohn, Muzzey, Maas, \& McCauley, 2019). Data collected by Flood (2019) also suggest 
that while \#MeToo led to some men reflecting on their own behaviours in sexual interactions and role they played in perpetuating rape culture, many still believe that women lie about rape and that sexual violence is not that serious a problem. Nonetheless, the hashtag offers some inroads into how we might better engage men in violence prevention post-\#MeToo (PettyJohn et al., 2019). The use of 'male allies' by the Pixel Project may be one effective way to involve men within anti-rape activism that does not digress from focussing on the fact that rape is by far a gendered experience. However, Angela's comment that men are more likely to listen to other men reveals the extent to which feminist discourse and ideas need to be more or less palatable. In other words, anti-rape activists continue to have to meet men on their own terms. Activist efforts should continue to challenge the impact of socially constructed behaviours associated with masculinity, the structural conditions that regulate women's bodies, the widespread behaviours that proliferate rape culture and the extent to which these ideologies filter through institutional understandings and responses to sexual violence.

This book has provided a nuanced contribution to understandings about the nature, use and scope of online spaces for anti-rape activism, in particular, the complexities regarding being heard, seen and believed, as well as the challenges involved in managing the competing demands between the personal and the political. While these online spaces might not be able to end rape, their existence is nonetheless a testament to the tireless efforts of anti-rape activists to ensure rape's presence is secure on the public agenda. It is my hope that this book and these concluding remarks will be useful in developing an agenda for change that is meaningful and impactful in reflecting on the significance and challenges associated with meeting the initial goals set out by second-wave feminists - to abolish rape in our lifetimes. 